\title{
MICROMORFOLOGIA FoliAR DE ESPÉCIES DE Sida spp. (guanXumas)'
}

\author{
Leaf Micromorphology of Sida spp. Species (prickly sida)
}

ALBERT, L.H.B. ${ }^{2}$ e VICTORIA FILHO, R. ${ }^{3}$

\begin{abstract}
RESUMO - A eficácia dos herbicidas aplicados à folha é influenciada pela morfologia da superfície foliar que recebe a calda. A topografia da superfície foliar, o grau e o tipo da formação da cera epicuticular e a presença, tipo e distribuição de tricomas são características que influenciam a distribuição da calda pulverizada sobre a superfície foliar e, conseqüentemente, a eficácia do controle da planta daninha. Diante desses fatos, o presente trabalho teve como objetivo conhecer morfologicamente a superfície foliar de três espécies de guanxuma (Sida rhombifolia, Sida glaziovii e Sida cordifolia). A pesquisa foi desenvolvida no Núcleo de Apoio à Pesquisa em Microscopia Eletrônica Aplicada à Pesquisa Agropecuária (NAP/MEPA), instalada na ESALQ/USP-Piracicaba/SP. As amostras biológicas foram fixadas, posteriormente desidratadas, secas ao ponto crítico e recobertas com ouro. Após a evaporação com metal, as amostras das folhas foram observadas em microscópio eletrônico de varredura Zeiss, operando entre 5 e $15 \mathrm{kV}$. Verificou-se que a superfície adaxial das espécies S. rhombifolia e S. glaziovii apresentou tricomas estelares e simples (não-ramificados), tanto curtos como longos, e também glandulares simples, tanto curtos como longos; S. glaziovii apresentou a maior quantidade destes. A espécie que apresentou maior presença de ceras epicuticulares foi S. rhombifolia, cuja aparência é estriada e a orientação aleatória. Das três espécies, S. cordifolia foi a que mostrou menor quantidade de tricomas, possuindo na superfície adaxial predominantemente tricomas simples e/ou com duas ramificações e também tricomas glandulares simples e curtos. A cutícula apresentou superfície plana e lisa, sem o aspecto estriado das outras duas espécies analisadas. Todas as espécies são anfiestomáticas, com predominância do tipo anomocítico, que é característico da família Malvaceae.
\end{abstract}

Palavras-chave: microscopia eletrônica de varredura, plantas daninhas, Malvaceae, cera epicuticular.

\begin{abstract}
The efficacy of leaf - applied herbicides is influenced by the morphological and physical-chemical characteristics of the leaf surface on which the herbicide solution is sprayed. The topography of the leaf surface, thickness of the cuticle, and the degree and type of epicuticular wax and the presence and type of trichomes, are characteristics that influence the distribution of the herbicide spray solution on the leaf surface and thus the efficacy of weed control. Therefore, the objective of this experiment was to obtain information on the morphological characteristics of three foliar surfaces of prickly sida (Sida rhombifolia, Sida glaziovii and Sida cordifolia). The experiment was conducted at the Electronic Microscopic Center Applied to Agriculture (NAP/MEPA), of Escola Superior de Agricultura "Luiz de Queiroz", Universidade de São Paulo, Piracicaba-SP, Brazil. The experiment using electronic microscopy technique showed that the species S. rhombifolia presented a higher amount of epicuticle-striped wax while the species S. cordifolia presented a flat and smooth cuticle. The species $\mathbf{S}$. glaziovii showed the highest amount of trichomes on the adaxial foliar surface. All the species analyzed had stomata in both surfaces of the leaves, with a predominance of the anomocytic type.
\end{abstract}

Key words: scanning electron microscopy, weeds, Malvaceae, epicuticular wax.

1 Recebido para publicação em 15/8/2002 e na forma revisada em 9/12/2002.

Parte da dissertação de mestrado do primeiro autor.

2 Eng.-Agr., M.S., Doutoranda do Departamento de Agricultura da Universidade Federal de Lavras UFLA, Caixa Postal 37, 37200-000 Lavras-MG, <lalbert@ufla.br>. ${ }^{3}$ Professor Titular do Departamento de Produção Vegetal da ESALQ/USP, 13418-900 Piracicaba-SP. 


\section{INTRODUÇÃO}

A membrana cuticular (MC), ou cutícula, é a primeira barreira à entrada de produtos químicos aplicados via foliar. Dessa forma, muitos estudos têm enfatizado a sua natureza e os fatores que influenciam a sua permeabilidade (Holloway, 1982; Bucovak et al., 1990). A cutícula pode ser definida pela sua posição anatômica ou natureza química. Quimicamente, ela é caracterizada por dois grupos específicos de substâncias lipídicas: cutinas, as quais constituem uma estrutura de suporte da membrana; e ceras depositadas sobre a superfície externa, denominadas ceras epicuticulares, e também firmemente dispersas no interior da matriz de cutina, logo abaixo da superfície, chamada de ceras cuticulares (Holloway, 1982; Baker, 1982; Devine et al., 1993).

As ceras epicuticulares, pertencentes à camada mais externa, podem ser amorfas ou depositadas em variáveis formas físicas; em algumas espécies elas formam uma camada plana, achatada, ao passo que em outras elas são prensadas na forma de lâminas ou cristais, com vasta extensão em termos de tamanho e forma. Estes cristais podem ter estruturas definidas como cristalinas ou semicristalinas (Baker, 1982; Devine, 1990). Essas diferenças nos padrões cuticulares podem ser taxonomicamente úteis em termos genéricos e mesmo entre espécies (Metcalfe \& Chalk, 1979; Cutter, 1986). A cera pode ser depositada em flocos grandes ou pequenos, em grânulos, hastes, tubos ou lâminas, que podem estar esculpidos em cumes ou outras formas. As condições sob as quais as plantas se desenvolvem podem afetar a forma da cera. Os padrões de cera podem variar em diferentes espécies e em alguma extensão dentro da mesma espécie, sob condições ambientais diferentes (Baker, 1982; Price, 1982). A formação da cera aparentemente começa num estágio inicial do desenvolvimento da folha e persiste até o final; as projeções parecem alcançar densidade e comprimento bastante uniformes e então permanecem relativamente inalteradas (Camargo \& Silva, 1975; Hess, 1985).

Na maioria das plantas, a cutícula não é estrutural e quimicamente homogênea, mas composta por um número de camadas, cada qual definida em virtude de sua posição ou constituição química. Dessa forma, já que em número, espessura e demarcação essas camadas variam consideravelmente de espécie para espécie e também conforme o estágio de desenvolvimento da planta, é sempre inviável apresentar um esquema simples generalizado de construção da cutícula. Além disso, as superfícies foliares não são planas, mas consistem de áreas com elevações e depressões, podendo incluir diversos padrões de ceras epicuticulares, tricomas, estômatos e glândulas (Holloway, 1982).

Muitas vezes, diferentes tipos de aspereza são encontrados na superfície da cutícula e diferenças marcantes em densidade e tipos de tricomas podem ocorrer até na mesma espécie, como entre a superfície adaxial e a abaxial na mesma folha. Há grande diversidade na morfologia da epiderme foliar entre as várias espécies, e o conhecimento dessas características é de grande importância para que se compreenda o comportamento do herbicida a ser absorvido (Hess \& Falk, 1990).

Uma área pequena de contato entre a gotícula da calda pulverizada e a superfície da cutícula pode limitar o potencial para a difusão entre a calda e a cutícula; logo, todos os aspectos das superfícies foliares (topografia das células, grau e tipo de desenvolvimento da cera epicuticular, tricomas e glândulas) influenciam a deposição do herbicida nas superfícies foliares. Abutilon theophrasti, por exemplo, possui tricomas simples e ramificados, enquanto Chenopodium album apresenta tricomas glandulares na superfície epidermal, que se tornam tão abundantes, que a superfície é quase oclusa (Hess \& Falk, 1990). As superfícies podem ser relativamente macias (Beta vulgaris), enrugadas (Syringa vulgaris) ou com papilas. Espécies glaucas são caracterizadas por cobertura adicional de ceras epicuticulares cristalinas, como Brassicas spp. e Pisum sativum. As características da superfície foliar influenciam o padrão da distribuição dos herbicidas. Superfícies cerosas e com abundante número de tricomas são geralmente os alvos mais difíceis de serem molhados, por serem hidrorrepelentes (Holloway, 1993).

De acordo com Ruiter et al. (1990) e Nalewaja et al. (1992), a retenção das gotas pulverizadas é melhor em plantas que possuem 
folhas com superfície cuticular plana do que naquelas que possuem folhas com superfície contendo ceras epicuticulares cristalinas. Da mesma forma, Hess \& Falk (1990) demonstram como as características da superfície foliar causam diferentes modelos de distribuição da calda sobre esta. Em superfícies foliares com pouco desenvolvimento das ceras epicuticulares, como a folha de B. vulgaris, as gotas do herbicida expandem-se, formando grandes áreas, e produzem depósitos nas depressões das paredes anticlinais. Quando o mesmo herbicida é aplicado em folhas com grande desenvolvimento das ceras epicuticulares, como a espécie Cynodon dactylon, os depósitos são menores e pequena área é coberta pelo herbicida, reduzindo assim a porcentagem de cobertura das células.

Estudos também têm sido feitos para avaliar a absorção, levando em consideração a presença de tricomas. Ricotta \& Masiunas (1992) avaliaram 14 genótipos de tomate e obtiveram correlação inversa entre a atividade de acifluorfen em determinado genótipo e a freqüência de tricomas (quanto mais tricomas, menos atividade). Dayan et al. (1996) demonstraram que as folhas da espécie Senna obtusifolia não retiveram as gotas da calda contendo herbicida sulfentrazone quando não foi usado nenhum surfatante. Essa ausência de surfatante apresentou relação inversa entre a quantidade de cera cuticular e a quantidade de herbicida absorvido. Plantas com mais ceras cuticulares, como Senna occidentalis e S. obtusifolia, absorveram relativamente menos sulfentrazone do que espécies com quantidades menores de ceras.

Diante desses fatos, o objetivo deste trabalho foi descrever a micromorfologia foliar de três espécies de guanxuma (Sida rhombifolia, Sida glaziovii e Sida cordifolia), com o uso do microscópio eletrônico de varredura.

\section{MATERIAL E MÉTODOS}

A pesquisa foi realizada no Núcleo de Apoio à Pesquisa em Microscopia Eletrônica Aplicada à Pesquisa Agropecuária (NAP/MEPA), situado na Escola Superior de Agricultura "Luiz de Queiroz"-USP.

As plantas das espécies de guanxuma (Sida rhombifolia, S. glaziovii e S. cordifolia) cresceram em casa de vegetação. Coletaram-se três folhas por vaso, por espécie, selecionadas no terço médio da planta, quando elas apresentavam estágio foliar de crescimento relativo a oito a dez pares de folhas. Foram seccionados segmentos de partes variadas das folhas, em fragmentos com tamanho aproximado de $5 \mathrm{~mm}^{2}$, e fixados em solução contendo glutaraldeído e paraformaldeído (Karnovsky, 1965), para estudo tanto da superfície adaxial como da abaxial.

Utilizou-se o protocolo-padrão do NAP/ MEPA (Kitajima \& Leite, 1998). O material foi fixado em Karnovsky modificado e pós-fixado em tetróxido de ósmio $\left(\mathrm{OsO}_{4}\right)$ 1\%, em tampão cacodilato $0,05 \mathrm{M}$, por mais uma hora e lavado em água destilada. As amostras do material foram desidratadas em soluções de concentrações crescentes de acetona e secas ao ponto crítico através de $\mathrm{CO}_{2}$ líquido. $\mathrm{O}$ aparelho de secagem ao ponto crítico usado no experimento foi o modelo CPD 050 de Balzers. As amostras secas ao ponto crítico devem ser imediatamente recobertas com ouro, para evitar sua reidratação.

Se o espécimen em estudo, embora rígido mas não metálico, for examinado diretamente, gerará imagens com problemas. Isso pode ser evitado evaporando o metal (em geral ouro) a vácuo em um metalizador, estando a amostra em uma mesa rotativa, para que o metal cubra todos os detalhes da superficie uniformemente. Uma maneira eficiente de se proceder a essa deposição metálica é utilizar um sistema conhecido como sputtering. $\mathrm{O}$ aparelho usado no experimento foi o metalizador MED 010 da Balzers; foi feita uma deposição de ouro durante 150 segundos.

Após a evaporação com metal, as amostras das folhas foram observadas em microscópio eletrônico de varredura Zeiss, modelo DSM 940A, operando entre 5 e $15 \mathrm{kV}$.

\section{RESULTADOS E DISCUSSÃO}

Segundo Metcalfe \& Chalk (1979) e Mauseth (1988), as dicotiledôneas possuem tipicamente as paredes anticlinais das células epidérmicas com aspectos sinuosos (ondulados). Sida rhombifolia, S. glazioviie S. cordifolia mostraram claramente essa característica em todas as figuras apresentadas. 


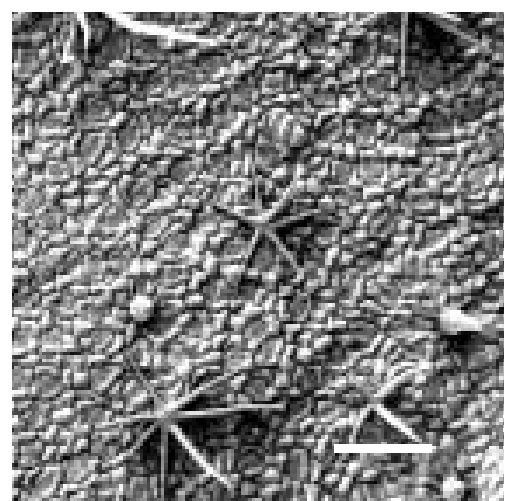

Figura 1 - Superfície adaxial da folha de S. rhombifolia. Vista geral da epiderme. Presença de estômatos, tricomas estelares e glandulares. Barra: $50 \mu \mathrm{m}$.

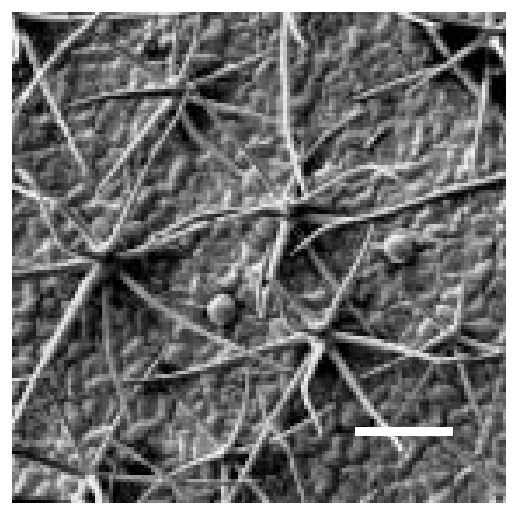

Figura 4 - Superfície adaxial da folha de S. glaziovii. Vista geral da epiderme. Presença abundante de tricomas estelares e alguns glandulares. Barra: $50 \mu \mathrm{m}$.

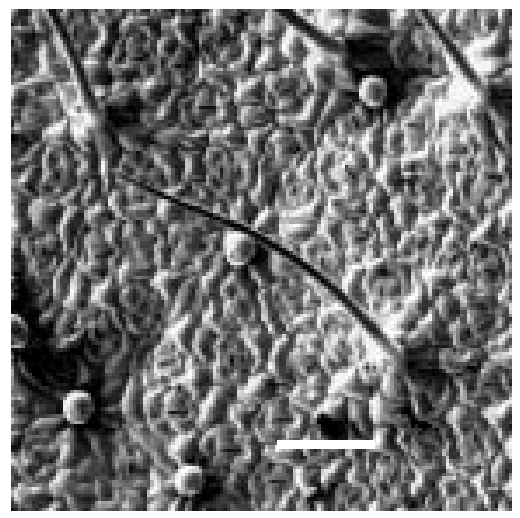

Figura 7 - Superfície adaxial da folha de S. cordifolia. Vista geral da epiderme. Presença de tricomas simples e glandulares. Barra: $50 \mu \mathrm{m}$.

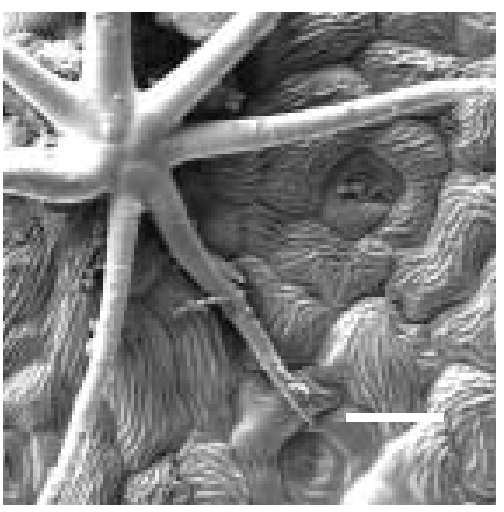

Figura 2 - Superfície adaxial da folha de $S$. rhombifolia. Detalhe de tricoma estelar, cera epicuticular estriada e estômato. Barra: $5 \mu \mathrm{m}$.

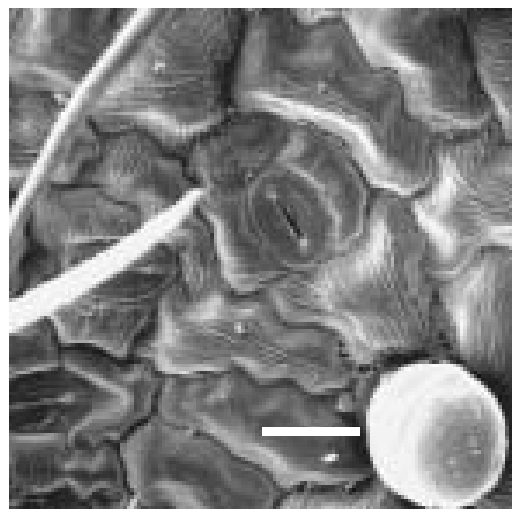

Figura 5 - Superfície adaxial da folha de $S$. glaziovii. Detalhe de tricoma glandular, estômato e cera epicuticular pouco estriada. Barra: $5 \mu \mathrm{m}$.

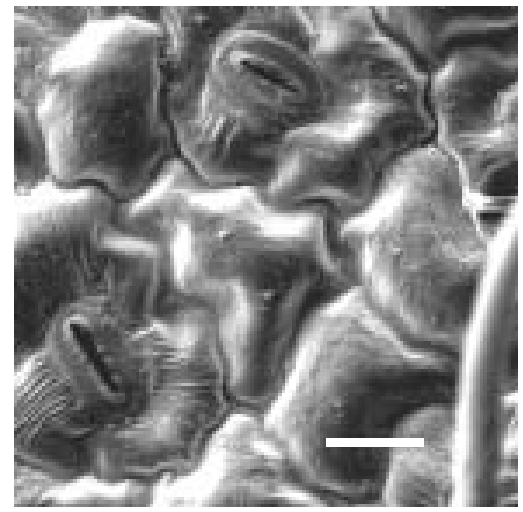

Figura 8 - Superfície adaxial da folha de $S$. cordifolia. Detalhe de cera epicuticular amorfa. Superfície lisa. Barra: $5 \mu \mathrm{m}$.

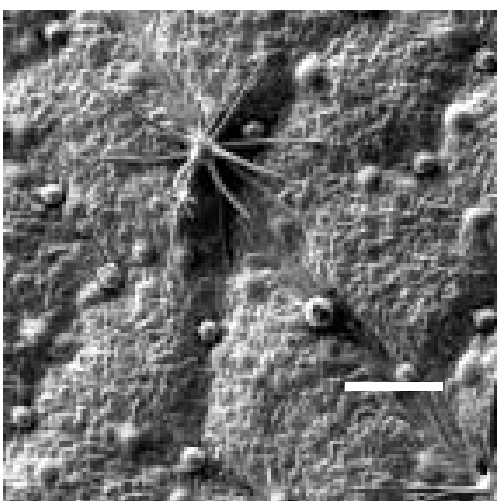

Figura 3 - Superfície abaxial da folha de $S$. rhombifolia. Vista geral da epiderme. Presença de tricomas estelares, glandulares e estômatos. Barra: $50 \mu \mathrm{m}$.

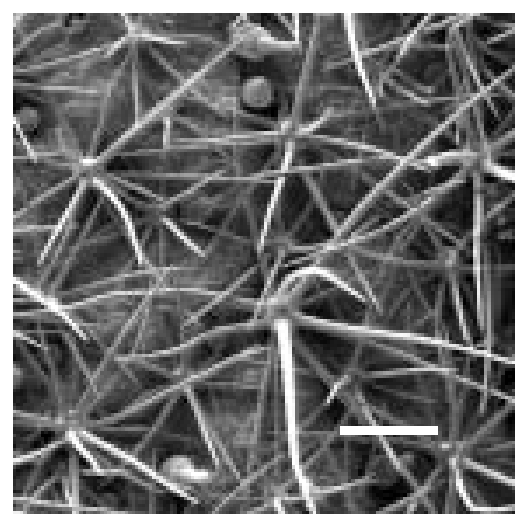

Figura 6 - Superfície abaxial da folha de S. glaziovii. Vista geral da epiderme. Presença abundante de tricomas estelares. Barra: $50 \mu \mathrm{m}$.

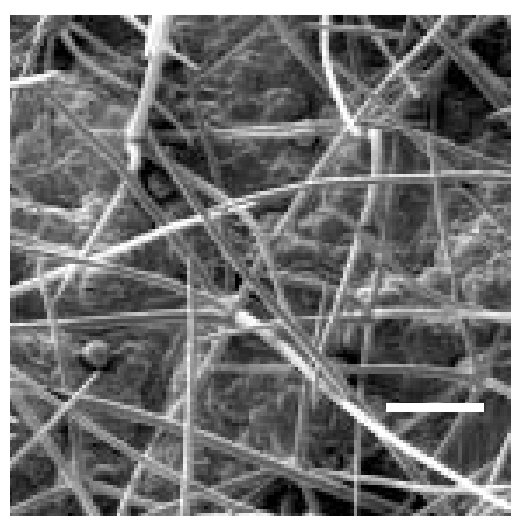

Figura 9 - Superfície abaxial da folha de S. cordifolia. Vista geral da epiderme. Presença abundante de tricomas estelares. Barra: $50 \mu \mathrm{m}$. 
Todas as espécies apresentaram estômatos em ambas as faces (superfícies adaxial e abaxial), sendo, portanto, anfiestomáticas. Metcalfe \& Chalk (1979) deram nomes descritivos a diversos tipos de estômatos; na família Malvaceae, o estômato que ocorre é do tipo anomocítico ou de células irregulares, em que as células que circundam o estômato são em número indefinido e não diferem das outras células epidérmicas.

Segundo Solereder (1908) e Metcalfe \& Chalk (1979), a família Malvaceae é caracterizada por possuir tricomas simples (nãoramificados) glandulares ou não, ramificados não-glandulares e estelares não-glandulares, podendo ocorrer vários desses tipos em uma mesma espécie.

A superfície adaxial de S. rhombifolia apresentou pequeno número de tricomas estelares e simples, tanto curtos como longos, e glandulares simples, tanto curtos como longos, bem como estômatos dispersos de forma aleatória na superfície foliar (Figura 1). A principal característica observada na superfície adaxial de S. rhombifolia foi a presença abundante de ceras epicuticulares estriadas com orientação aleatória (Figura 2), conforme descrição de Metcalfe \& Chalk (1979). Essas ceras também estão presentes na superfície abaxial da espécie, que apresentou grande número de tricomas glandulares e a presença de tricomas estelares (Figura 3).

Conforme Solereder (1908) e Cutter (1986), é comum nessa família a ocorrência de vários tipos de tricomas glandulares na mesma espécie. Esses autores afirmam que esses tricomas possuem um pedúnculo e uma cabeça; o pedúnculo pode ser unicelular ou multicelular e, pode mesmo ter várias fileiras de células. A cabeça, que é a parte secretora, também pode ser unicelular ou multicelular.

S. glaziovii mostrou grande número de tricomas glandulares simples, tanto curtos como longos (Figuras 4 e 6). Ela também apresentou acentuado número de tricomas estelares, que foi a característica mais marcante nessa espécie tanto na superfície adaxial como na abaxial; nesta última a superfície ficou quase oclusa (Figuras 4 e 6). Em relação à sua ornamentação cuticular, essa espécie apresentou ceras epicuticulares também estriadas, mas não tão evidentes como em S. rhombifolia. Os estômatos também são do tipo anomocítico e se encontram um pouco abaixo da superfície (Figura 5).

A espécie $S$. cordifolia mostrou na superfície adaxial pouco número de tricomas, possuindo predominantemente tricomas simples (não ramificados) e/ou com duas ramificações, bem como tricomas glandulares simples e curtos (Figura 7). A cutícula apresentou-se plana e lisa, sem o aspecto estriado das outras duas espécies analisadas (Figura 8).

S. cordifolia apresenta estômatos anomocíticos, característico da família. A superfície abaxial apresentou abundância nos tricomas estelares, aparentando muita proximidade com a espécie S. glaziovii (Figura 9).

Foy \& Takeno (1992), estudando as superfícies foliares de Sida spinosa, comentaram que elas aparentam ser planas e lisas a olho nu. No entanto, numerosos tricomas foram observados em ambas as superfícies das folhas através de microscópio eletrônico de varredura, mostrando a relevância do uso desta técnica para melhor descrição de aspectos micromorfológicos das espécies. Harr et al. (1991) demonstraram que, diferentemente das três espécies aqui analisadas, $S$. spinosa apresenta apenas tricomas simples e glandulares.

Mendonça et al. (2002), na caracterização da espécie $S$. rhombifolia, não constataram a presença de tricomas estelares na sua superfície adaxial, diferentemente do resultado da pesquisa feita por Albert (2000), talvez pela diferença no estágio de desenvolvimento foliar quando da coleta das folhas.

Os diversos trabalhos que vêm sendo realizados com caracterização ultra-estrutural de superfícies foliares (Albert, 2000; Mendonça, 2000; Monquero et al., 2002; Santos et al., 2002) demonstram a importância do maior conhecimento das diferentes espécies para uma possivel correlação entre essas características e diferenças de absorção entre herbicidas, além da utilização da microscopia eletrônica de varredura como ferramenta para caracterização das espécies e de suas estruturas foliares. 


\section{LITERATURA CITADA}

ALBERT, L. H. B. Características morfológicas da cutícula foliar e efeitos de adjuvantes no controle químico de espécies de guanxumas (Sida spp). Piracicaba: Escola Superior de Agricultura "Luiz de Queiroz", 2000. 94 p. Dissertação (Mestrado em Fitotecnia) - Escola Superior de Agricultura Luiz de Queiroz, 2000.

BAKER, E. A. Chemistry and morphology of plant epicuticular waxes. In: CUTLER, D. F.; ALVIN, K. L.; PRICE, C. E. (Eds.) The plant cuticle. London: Academic Press, 1982. p. 139-165.

BUKOVAC, M. J. et al. Sorption of organic compounds by plant cuticle. Weed Sci., v. 38, p. 289-298, 1990.

CAMARGO, P. N.; SILVA, O. Manual de adubação foliar. São Paulo: Herba, 1975. 258 p.

CUTTER, E. G. Anatomia vegetal. São Paulo: Roca, 1986. 304 p.

DAYAN, F. E. et al. Postemergence activity of Sulfentrazone: effects of surfactants and leaf surfaces. Weed Sci., v. 44, p. 797-803, 1996.

DEVINE, M. D. Mechanisms of herbicide absorption and translocation in plants. Weed Sci., v. 38, p. 279, 1990.

DEVINE, M. D.; DUKE, S. O.; FEDTKE, C. Physiology of herbicide action. London: Prentice Hall, 1993. 441 p.

FOY, C. L.; TAKENO, T. Effect of polisorbate surfactants with various hydrophilic-lipophilic balance ( HLB ) values on leaf surface ultrastructure and mobility of methazone in plants and soil. In: FOY, C.L. (Ed.) Adjuvants for agrichemicals. Boca Raton: CRC Press, 1992. p. 169-185.

HARR, J. et al. The leaf surface of major weeds. Witterswil: Sandoz Agro, 1991. 133 p.

HESS, F. D. Herbicide absortion and translocation and their relationship to plant tolerances and susceptibility. In: DUKE, S.O. Weed Physiol., v. 2, p. 192-214. 1985.

HESS, F. D.; FALK K. H. Herbicide deposition on leaf surfaces. Weed Sci., v. 38, p. 280-288, 1990.

HOLLOWAY, P. J. Structure and histochemistry of plant cuticular membranes: an overview. In: CUTLER, D. F.; ALVIN, K. L.; PRICE, C. E. (Eds.) The plant cuticle. London: Academic Press, 1982. p. 1-32.

HOLLOWAY, P. J. Structure and chemistry of plant cuticles. Pesticide Sci., v. 37, p. 203-206, 1993.
KARNOVSKY, M. S. A formaldehyde - glutaraldehyde fixative of high osmolality for use in electron microscopy. J. Cell Biol. v. 27, p. 137-138, 1965.

KITAJIMA, E. W.; LEITE, B. Curso introdutório de microscopia eletrônica de varredura. 1998. 37 p.

MAUSETH, J. D. Plant anatomy. Menlo Park: Benjamin/ Cummings, 1988. $560 \mathrm{p}$.

MENDONÇA, C. G. Algumas características da superfície foliar de diversas plantas daninhas monocotiledôneas. Botucatu: Universidade Estadual Paulista, 2000. 89 p. Dissertação (Mestrado em Agronomia) - Universidade Estadual Paulista, 2000.

MENDONÇA, C. G. et al. Características ultra-estruturais das superfícies foliares de plantas daninhas dicotiledôneas. In: CONGRESSO BRASILEIRO DA CIÊNCIA DAS PLANTAS DANINHAS, 23., 2002, Gramado, RS. Resumos... Londrina: SBCPD, 2002. p. 22.

METCALFE, C. R.; CHALK, L. Anatomy of the dicotyledons. 2.ed. Oxford: Claredon Press, 1979. v.1. $276 \mathrm{p}$.

MONQUERO, P. A; CHRISTOFFOLETI, P. J.; PRADO, R. A. Absorção e translocação de ${ }^{14} \mathrm{C}-$ glyphosate e análise da superfície foliar e ceras epicuticulares de plantas tolerantes e suscetíveis a este herbicida. In: CONGRESSO BRASILEIRO DA CIÊNCIA DAS PLANTAS DANINHAS, 23., 2002, Gramado, RS. Resumos... Londrina: SBCPD, 2002. p. 186.

NALEWAJA, J. D.; MATYSIAK, R.; FREEMAN, T. Spray droplet residual of glyphosate in various carriers. Weed Sci., v. 40, p. 576-589, 1992.

PRICE, C. E. A review of the factors influencing the penetration of pesticides through plant leaves. In: CUTLER, D. F.; ALVIN, K. L.; PRICE, C. E. (Eds.) The plant cuticle. London: Academic Press, 1982. p. 237-252.

RICOTTA, J. A.; MASIUNAS, J. B. Relantionship of leaf surface characteristics to acifluorfen tolerance in tomato (Lycopersicon esculentum) and related species. Weed Sci., v. 40, p. 402-407, 1992.

RUITER, H. D. et al. Influence of surfactants and plant species on leaf retention of spray solutions. Weed Sci., v. 38, p. 567-572, 1990.

SANTOS, I. C. et al. Caracteres anatômicos de duas espécies de trapoeraba e a eficiência do Glyphosate. Planta Daninha, v. 20, p. 1-8, 2002.

SOLEREDER, H. Systematic anatomy of the dicotyledon. Oxford: Claredon Press, 1908. v.1. 644 p. 